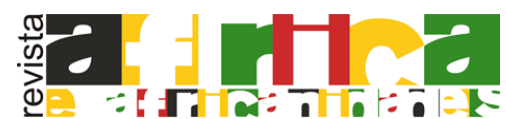

Revista África e Africanidades - Ano XIII - n. 34, maio. 2020 - ISSN 1983-2354

www.africaeafricanidades.com.br

ARTIGO

\title{
Percursos e desafios da educação inclusiva na África Austral: caso de Moçambique
}

\author{
Hélio Daniel Parruque ${ }^{1}$
}

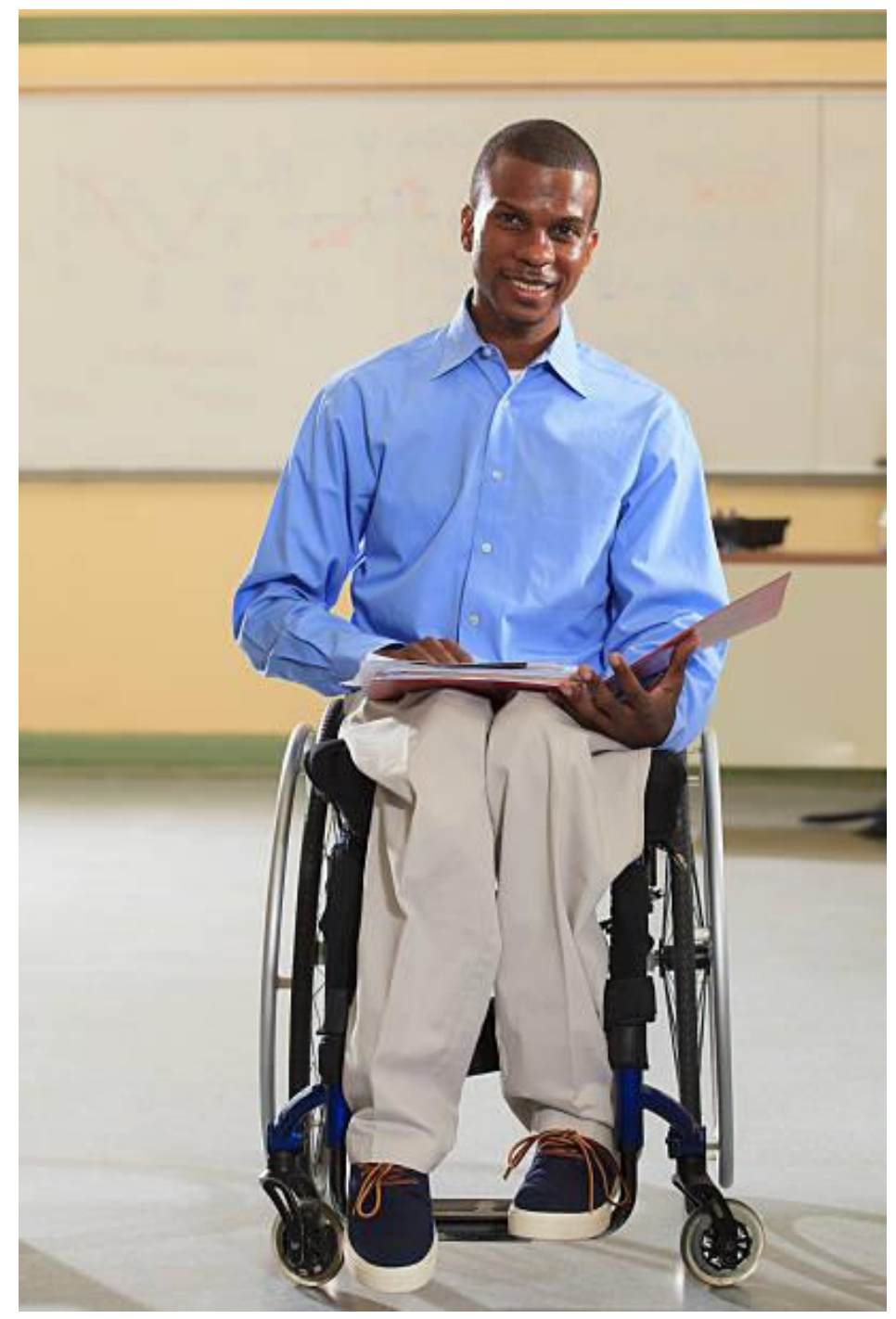

\footnotetext{
1 Mestre em Administração e Gestão Escola pela Universidade Pedagógica de Maputo Moçambique. Doutorando em Educação e Infância na Universidade Federal de Santa Catarina. E-mail: hagazpipa60@gmail.com
} 


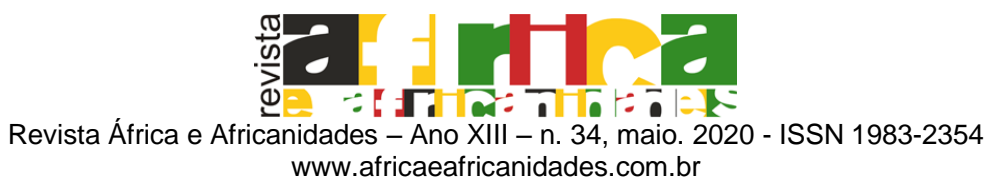

RESUMO: O presente artigo tem como objetivo analisar os percursos e os desafios da educação inclusiva na África Austral e em particular em Moçambique partindo dos princípios básicos vinculados em diferentes documentos internacionais e regionais cujo país é signatário. Trata-se de um estudo documental em que analisamos as diretrizes contidas em diversos documentos referenciais como é o caso da Declaração de Salamanca que versa sobre Princípios, Políticas e Práticas na Área das Necessidades Educativas Especiais, Declaração dos direitos das pessoas deficientes Resolução aprovada pela Assembleia Geral da Organização das Nações Unidas em 09/12/75, A Declaração Mundial Jomtien sobre Educação para Todos (1990) que estabelece compromissos em torno de currículos, ensino e aprendizagem centrados na criança e que tenham maior consideração na diversidade, Normas da ONU sobre Igualdade de Oportunidades para as Pessoas com Deficiência (1993) que sublinha a importância da realização dos direitos humanos básicos das pessoas com deficiências que tenham sido alvo de discriminação assim como a Estratégia de educação inclusiva para alunos com deficiência na África Austral (SAIES) 2017 - 2021. No que diz respeito à metodologia ressaltamos que foi crucial contar com a documentação acima citada relacionando-a com os contextos educativos que caracterizam os avanços e os desafios da educação em Moçambique no que concerne à inclusão de pessoas com deficiências nas escolas regulares num momento em que o país definiu para o presente ano letivo como lema "Por uma Educação Inclusiva, Patriótica e de Qualidade" mesmo com considerado número de crianças com diversas necessidades educativas especiais que por razões várias estão apenas experimentando a integração para além da verdadeira inclusão.

PALAVRAS-CHAVE: educação inclusiva; Moçambique; deficiência.

\section{INTRODUÇÃO}

O presente artigo toma como mote investigativo os percursos e os desafios da educação inclusiva na África Austral e em particular em Moçambique em que o atual sistema educacional baseia-se, no modelo de integração em que todos os alunos devem seguir o mesmo método pedagógico, avançar no mesmo ritmo e ser avaliados da mesma forma, contrário do que é a prescrição duma educação inclusiva que inclui a todos, sem discriminação, e a cada um, com suas diferenças, independentemente de sexo, idade, religião, origem étnica, raça ou mesmo deficiência. Uns dos maiores desafios que caracterizam o sistema educacional moçambicano no contexto da inclusão são as oportunidades iguais para todos e estratégias diferentes para cada um, de modo que todos possam desenvolver seu potencial.

No ano em que Moçambique alcançou a independência em 1975 existiam apenas 4 Escolas Especiais privadas, sendo duas na Cidade de Maputo (Deficiência Auditiva e Mental), duas na província de Sofala (Deficiência Auditiva e o Instituto Nacional dos Deficientes Visuais) e uma na cidade de Nampula (Deficiência Mental) as quais foram nacionalizadas. Estas instituições tinham uma tripla subordinação, nomeadamente Saúde (assistência médica), Acção Social (apoio social) e a Educação (ação levada a cabo por professores), programas de estudo e o apoio directo às escolas.

Após quatro anos da Declaração de Salamanca em 1994 Moçambique adaptou em 1998, a política de educação inclusiva, implementando, assim, o Projeto-Piloto em cinco províncias, nomeadamente: Cidade de Maputo, 


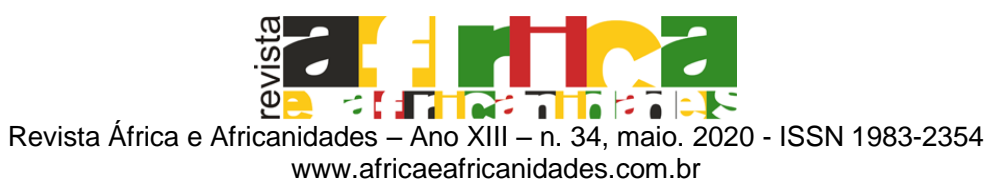

província de Maputo, Sofala, Zambézia e Nampula.como resposta às orientações da Conferência Mundial sobre Necessidades Educativas Especiais.

De acordo com os dados do Ministério da Educação e Desenvolvimento Humano, em 2003-2005, já frequentavam as escolas regulares de todo o país cerca de 31.000 crianças e jovens com NEE, 418 que exigiam uma atenção mais especializadas foram integradas nas 6 escolas/turmas especiais (Maputo, Sofala, Manica, Tete, Zambézia, Nampula e Niassa).

A criação de turmas especiais nas escolas regulares visavam escolarizar alunos com Necessidades Educativas Especiais (NEE) Auditivas, Visuais e Mentais atendidos por professores com competências básicas de Língua de Sinais Moçambicano, Sistema Braille e respectivas metodologias para o processo de ensino aprendizagem. Mas, as actividades extracurriculares, Educação Física e outros fazem em conjunto.

Em 2007/2008 frequentaram as Escolas do Ensino Primário Regular aproximadamente 89.125 alunos com NEE (maior incidência na escrita, cálculo) dos quais 3.560 são mulheres e nas 6 escolas especiais e /ou turmas inclusivas foram atendidas 440 alunos dos quais 176 mulheres com destaque em Maputo, Sofala, Tete, Manica, Quelimane e Nampula.

Neste momento, cerca de 100 mil alunos com Necessidades Educativas Especiais (NEE), nomeadamente dificuldades de aprendizagem, comportamento e emocional, transtornos de fala, deficiências auditiva, visual, mental físico-motor, entre outros, frequentam as escolas do Ensino Primário, Secundário, Técnico-Profissional e Superior, incluindo alunos das Escolas/Turmas Especiais (600), dos Centros de Recursos de Educação Inclusiva (232).

No Ensino Superior foram integrados 17 estudantes, sendo 15 com deficiência visual dos quais 5 mulheres, sendo 17 estudantes Deficientes Visuais, sendo 15 com deficiência visual dos quais 5 mulheres, sendo 6 na Universidade Pedagógica de Maputo (História, Educação. Infância, Psicologia Escolar), 4 Universidade Pedagógica Beira (História, Inglês, Geografia), 3 Universidade de Porto/ Lisboa em Portugal (Sociologia), 1 Instituto Superior Politécnico e Universitário em Maputo (Direito), 1 na Universidade Eduardo Mondlane (Sociologia) e 2 Estudantes com Deficiência Auditiva na Universidade Pedagógica (Gestão de Educação à Distancia).

\section{Contexto socioeconômico de Moçambique}

Moçambique está localizado na África Austral e ocupa um território de cerca de $800.000 \mathrm{~km}^{2}$, com uma população estimada em 27.909 .798 de pessoas, das quais 13.348 .446 são do sexo masculino correspondendo a $48 \%$ e 14.561 .352 do sexo feminino correspondendo a $52 \%$, de acordo com os resultados do IV Recenseamento Geral da População e Habitação, organizado e realizado pelo Instituto Nacional de Estatística (INE) em 2017. Quase dois terços da população vivem em áreas rurais e o terço restante em áreas urbanas. A maioria da população moçambicana é jovem, com cerca de metade dos seus cidadãos e cidadãs com menos de 18 anos. De acordo com o relatório do Fórum da Sociedade Civil para os Direitos da Criança - ROSC 


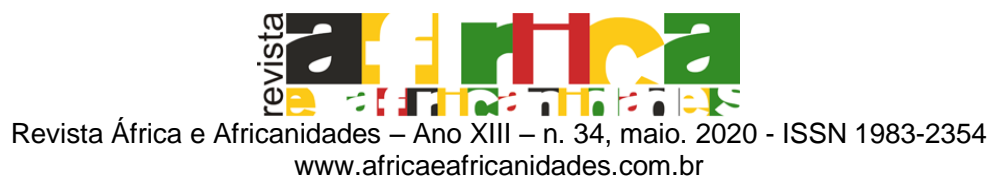

(2014), em Moçambique existem cerca de 475.011 pessoas com deficiência, equivalente a $2 \%$ do total da população. E paralelamente ao acima citado, 0 Censo populacional de 2007 do INE, indica que em Moçambique, as crianças representam cerca de $50 \%$ da população.

No entanto, tomando em consideração os dados do inquérito de Indicadores Múltiplos (MICS), do INE divulgados em 2008, cerca de 14\% destas Crianças com idades compreendidas entre dois e nove anos de idade tem algum tipo de deficiência. A surdez representa o tipo de deficiência mais comum, seguida pela deficiência mental. No entanto, dados do estudo sobre "Características Socioeconómicas da População com Deficiência em Moçambique", revelam que $68.1 \%$ de crianças com deficiência de 0 a 17 anos, não foram registadas, e a maior parte destas crianças reside nas zonas rurais. Por outro lado, as crianças com deficiência mental, surdas e cegas apresentam as taxas mais elevadas de analfabetismo. $E$ as crianças do sexo feminino são as que mais apresentam as taxas mais altas do problema. O INE revela também que a proporção de pessoas com deficiência que frequentam a escola é maior nas idades iniciais e vai reduzindo à medida que a idade avança.

\section{Desafios da educação inclusiva na África Austral e em particular em Moçambique}

De acordo com o Ministério da Educação e Desenvolvimento Humano O processo inclusivo enfrenta desafios devido a mobilidade de técnicos, diretores e professores de escolas formados/capacitados. Assim sendo e no âmbito de uma abordagem inclusiva, visando abranger alunos com Necessidades Educativas Especiais há necessidade de se prosseguirem ações e mudanças preconizadas pelo Plano Estratégico de 2012-2016 que possibilitem tanto o acesso, como a retenção, adaptações arquitectónicas às infra-estruturas escolares, desenvolvimento de programas para formação de professores, curricula flexíveis que respondam as características e necessidades de todos alunos, a organização de recursos técnicos de serviços e parcerias com as comunidades.

Em termos simples, os desafios de acesso à educação enfrentados pelas crianças com deficiência, especialmente nos contextos em desenvolvimento, têm um efeito profundo sobre o resto das suas vidas, restringindo a sua capacidade de participarem equitativamente e contribuírem significativamente para as suas sociedades e as torna muito mais vulneráveis em face da actual exclusão económica e social. A exclusão das crianças com deficiência de acesso à educação é ainda colocada com maior relevo pela UNESCO. Segundo a UNESCO, a deficiência é uma das manifestações da marginalização educacional menos visível, mas os seus factores são os mais potentes. Isso a despeito do facto de que o acesso à educação e subsequente sucesso educacional, é uma porta para a mudança em muitas áreas da vida das pessoas portadoras de deficiência.

O estudo efecuado pelo Secretariado da Década Africana de Pessoas com Deficiência (SADPD 2012) revela casos de limitado acesso à educação de qualidade no contexto de um sistema de educação inclusiva para os alunos portadores de deficiência. $O$ estudo identifica uma série de constrangimentos 


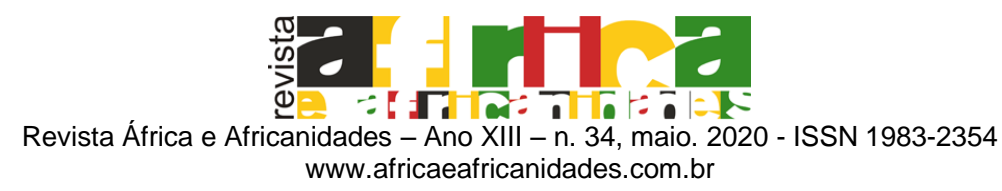

que contribuem para o limitado acesso à educação dos alunos com deficiência na região que são discutidos com maior detalhe mais abaixo:

\section{Leis e políticas conducentes}

Muitos Estados Membros da SADC reconhecem a exclusão dos alunos com deficiência dos seus sistemas de educação e tem manifestado empenho e resolver esta questão. O seu empenhamento é evidenciado no número de Estados Membros da SADC que adoptaram leis e políticas nacionais inclusivas que visam responder as necessidades dos alunos com deficiência. Estes quadros jurídicos e políticos inclusivos são apoiados e informados por instrumentos internacionais e regionais dos direitos humanos que foram assinados e ratificados pelos Estados Membros da Comunidade de Desenvolvimento da África Austral (SADC) cujo Moçambique é também membro.

Apesar da claridade plasmada nos diversos instrumentos reguladores e conducentes à educação inclusiva, há que salientar que os países da África Austral, em particular Moçambique enfrentam maiores desafios para a sua materialização. Um dos aspectos que merecem nossa análise é abordagem médica ou o modelo médico no tratamento das pessoas com deficiência.

Conforme analisado no país, dito de outro modo, os instrumentos acima referidos encaram as limitações físicas, mentais ou sensoriais da pessoa como problema central a resolver através da cura, adaptação ou reabilitação, prestação de serviços discriminatórios tais como cuidados domiciliários, escolas especiais e Centros do dia e não como problema social cuja solução passa pela remoção das barreiras ambientais e de atitudes na sociedade para a plena inclusão das pessoas com deficiência. Identificadas as fraquezas dos instrumentos jurídicos generalistas e universalistas, tornava-se cada vez mais evidente e imperioso a adopção de instrumentos jurídicos mais específicos para as pessoas com deficiência que incorporassem todas as necessidades peculiares desta categoria de seres humanos com toda a sua diversidade.

Esta abordagem nos elucida à necessidade de se apostar na abordagem social da deficiência de modo a construir-se uma sociedade cada vez mais inclusiva criando-se condições para que as barreiras físicas sejam removidas e desse modo a inclusão se torne efetiva.

Medeiros \& Diniz (2004) descrevem o ponto de partida teórico do modelo social da deficiência, segundo eles, na base deste modelo,

\footnotetext{
a deficiência é considerada uma experiência resultante da interação entre características corporais do indivíduo e as condições da sociedade em que ele vive, isto é, da combinação de limitações impostas pelo corpo com algum tipo de perda ou redução de funcionalidade ("lesão") a uma organização social pouco sensível à diversidade corporal. Deficiência: desvantagem ou restrição de atividade provocada pela organização social contemporânea que pouco ou nada considera aqueles que possuem lesões físicas e os exclui das principais atividades da vida social" (MEDEIROS \& DINIZ, 2004, p.8).
} 


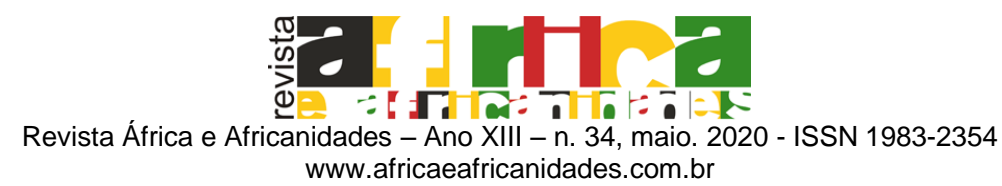

Foi na base do reconhecimento destas dificuldades de aplicação dos instrumentos internacionais de direitos humanos de natureza universalista e generalista para a solução de problemas reais e peculiares das pessoas com deficiência que, deste cedo, e no âmbito do sistema das Nações Unidas, começaram a ser dados passos, embora tímidos, rumo ao reconhecimento e autonomização dos instrumentos jurídicos sobre direitos das pessoas com deficiência. (2014)

De acordo com Corker \& Shakespeare (2010) apud Valle \& Connor

\begin{abstract}
nos últimos anos, as pessoas com deficiências, os especialistas em estudos dessa área e os defensores dos direitos dos deficientes distinguiram o impedimento da "deficiência" da seguinte maneira: um impedimento refere-se às variações que existem em comportamento, aparência, funcionamento, acuidade sensorial e processamento cognitivo humano, em contraste com as deficiências, que são um produto de práticas sociais, políticas económicas e culturais. Em outras palavras, há um jogo do que uma diferença biológica. Por exemplo, uma usuária de cadeira de rodas pode ter um impedimento que requer que ela se movimente pelo mundo de um modo que não seja caminhando; contudo, se a usuária de cadeira de rodas quer entrar em um edifício que é acessível apenas para pessoas que caminham, ela se torna deficiente pelo contexto. Dessa forma, a deficiência pode ser entendida como uma construção social. (VALLE \& CONNOR, 2014. p.62).
\end{abstract}

\title{
Dados não fiáveis e escassos sobre crianças com deficiência
}

A incipiente gestão de dados dificulta a recolha de informação precisa sobre como é que as leis e políticas inclusivas na região e a vontade política dos governos da SADC são traduzidos em intervenções para permitir o acesso e participação dos alunos com deficiência à educação na região (SADPD, 2012; Fórum de Política da Criança Africana (ACPF), 2010). São escassos ou pouco fiáveis os dados disponíveis sobre a prevalência da deficiência entre crianças, índices de inscrição dos alunos com deficiência nas instituições de ensino públicas e privadas, progresso feito pelos alunos, suas necessidades de apoio e recursos disponíveis para responder às suas necessidades. Nos países onde é possível reunir alguns dados sobre alunos com deficiência, os referidos dados são na maioria dos casos contraditórios e pouco fiáveis. Ademais, nos países onde existe alguma forma de dados sobre a educação de alunos, estes dados tendem a depender fortemente dos números de alunos que frequentam escolas especiais e limitada atenção é prestada à situação prevalecente nas escolas normais e em outras instituições de ensino.

Alguns dos fatores que contribuem para a escassez de dados ou dados pouco fiáveis sobre crianças com deficiência na região incluem entre outros 0 facto de que a deficiência ainda não figura nos processos estatísticos dos governos e as várias definições aplicada ao termo deficiência na região. A escassez e/ou pouca fiabilidade dos dados contribui para a exclusão e por vezes é responsável pela limitada inclusão de alunos com deficiência nos planos e programas dos governos.

Falta de sensibilização e atitude negativa para com a deficiência

A falta de sensibilização e a ignorância com respeito às aptidões e competências dos alunos com deficiência assim como as atitudes negativas 


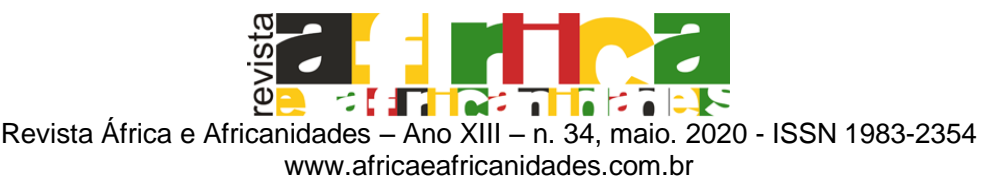

para com a deficiência em geral contribuem supostamente para a exclusão dos alunos com deficiência do sistema de educação. A falta de sensibilização, a ignorância e as atitudes negativas com respeito a deficiência é alicerçada e reforçada por crenças culturais que estigmatizam as pessoas portadoras de deficiência e perpetuam a sua discriminação e marginalização. Estas crenças incluem o pressuposto historicamente dominante em torno da deficiência, um pressuposto que considera as pessoas portadoras de deficiência como pessoas indefesas, incapazes de aprender e meros objectos de caridade, ao invés de cidadãos produtivos que gozam de direitos, incluindo o direito à uma educação de qualidade.

\section{Limitada capacidade humana para apoiar $o$ desenvolvimento e implementação de um sistema de educação inclusivo}

A limitada capacidade humana dotado dos necessários conhecimentos e competências a todos os níveis de educação foi identificada como um dos principais constrangimentos enfrentados pelos Estados Membros da SADC nos seus esforços para criar um sistema de educação inclusivo que responda às necessidades e aspirações dos alunos com deficiência. Os constrangimentos em termos de pessoal incluem a falta de gestores de educação para planear e gerir um sistema de educação inclusivo, bem como a falta de professores e de pessoal de apoio em números adequados e devidamente formados. A agravar este problema, é a falta de instituições de ensino superior na região para dotar os professores e outro pessoal de apoio dos necessários conhecimentos e competências para apoiar um sistema de educação inclusivo. Ademais, o estudo sugere que em muitos Estados Membros da SADC foram consentidos esforços muito limitados para mobilizar o apoio dos pais das crianças com deficiência e outros recursos existentes na comunidade em prol do processo de ensino e aprendizagem. Isso a despeito da evidência demonstrada pelo estudo dos benefícios positivos que poderiam advir dessa colaboração no incremento da capacidade humana para apoiar um sistema de educação inclusivo.

A esse, conforme alude Mantoan (2003, p.14) a inclusão implica uma mudança de perspectiva educacional, pois não atinge apenas alunos com deficiência e os que apresentam dificuldades de aprender, mas todos os demais, para que obtenham sucesso na corrente educativa geral.

\section{Currículos inacessíveis e inadequados}

Os Estados Membros da SADC registaram progressos na transformação dos seus programas curriculares. Todavia, os currículos colocam supostamente as principais barreiras ao acesso dos alunos com deficiência ao sistema de educação inclusivo (SADPD 2012). Por exemplo, em muitos Estados Membros da SADC, vários são os alunos com deficiência, especialmente os portadores de deficiência de índole intelectual, que enfrentam dificuldades de se identificarem com os currículos visto que estes focam estritamente em aspectos puramente académicos. A maioria dos currículos na região não são academicamente focadas, mas incorporam pontos de saída únicos. Ademais, os currículos tendem a ser rígidos e dificilmente modificáveis para acomodar a diversidade dos alunos e isso coloca desafios aos alunos com deficiência que carecem de diversificadas necessidades de aprendizagem. 


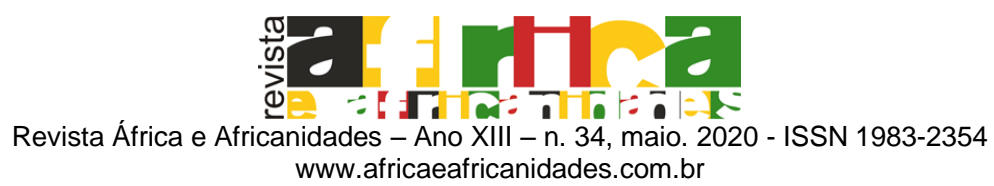

Como resultado do que precede, muitos alunos com deficiência são excluídos de participar nas atividades curriculares nacionais. Os poucos que têm a oportunidade de participar em tais atividades curriculares não conseguem obter os necessários materiais de ensino e aprendizagem e professores e pessoal de apoio para ajudá-los a enfrentar aspectos curriculares inflexíveis. Mesmo nos casos em que existam recursos adequados para apoiar os alunos, o estado não encoraja qualquer tentativa de modificação curricular devido ao receio de comprometer os padrões de ensino. Face aos currículos inflexíveis e ao ambiente de ensino desfavorável, muitos alunos com deficiência optam pelo abandono escolar e os poucos que optam por perseverar eventualmente saem do sistema de educação sem lograr adquirir os conhecimentos e as competências necessárias para o seu bem-estar socioeconómico.

A flexibilização curricular, como um dos desafios para a efetivação da educação inclusiva em Moçambique carece em primeiro plano da preparação da escola regular para receber os alunos considerados deficientes. Para além desta, deve se tomar em conta a necessidade de se adotar técnicas e recursos que auxiliem nessa ação sem descorar dos processos de formação de professores como o agente principal desse processo de inclusão de alunos considerados deficientes no ensino regular.

No que diz respeito à flexibilização curricular com vista a favorecer a inclusão dos alunos com necessidades educativas especiais nas escolas regulares Bonde (2016) alude que,

a inclusão requer transformações radicais de valores e concepções, com impactos nas práticas pedagógicas, no projeto institucional e nas adaptações do espaço físico, para assegurar as condições de acesso e permanência de todos os alunos e o clima de tolerância e respeito entre os diferentes. (BONDE, 2016, p.108).

\section{Recursos financeiros inadequados}

Há uma percepção geral de que a região enfrenta um desafio de penúria de recursos. Os recursos inadequados têm um impacto negativo sobre a prestação de serviços nos programas gerais e mais especificamente nos programas que visam grupos marginalizados. Isto inclui os programas focados no melhoramento do acesso à educação para alunos com deficiência. A vontade política reflectida pela adopção por muitos Estados Membros da SADC de quadros jurídicos e políticos sensíveis a problemática da deficiência não é acompanhada por dotações orçamentais para financiar os programas que permitam o acesso e a participação dos alunos com deficiência na educação de qualidade.

$\mathrm{Na}$ região, existe supostamente uma limitação da dotação orçamental para intervenções que focam na educação inclusiva. As limitadas dotações orçamentais e a ignorância acerca da deficiência são consideradas como contribuindo para a suposta infraestrutura de ensino que não é acessível aos alunos com deficiência, limitados materiais de apoio ao processo de ensino e aprendizagem e limitado número de pessoal de educação, incluindo professores e pessoal de apoio com os necessários conhecimentos e competências. Ademais, muitos Estados Membros da SADC dependem de fundos dos doadores para financiar projectos de educação inclusiva isolados, 


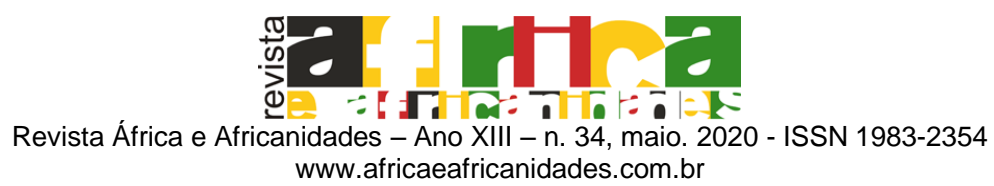

com limitados ou praticamente nenhuns recursos cometidos pelos governos recipientes. Estes projectos financiados por doadores muitas das vezes não são sustentáveis devido à falta ou muito pouco apoio dos governos.

Há indicações de que mesmo nos casos onde foram afectadas dotações orçamentais ao nível nacional para impulsionar iniciativas de educação inclusiva, especialmente nos sistemas fortemente descentralizados, na maioria das vezes, outras prioridades se sobrepõem e absorvem este financiamento, resultando na provisão inadequada de recursos para a educação inclusiva.

De acordo com o Governo de Moçambique (2018), ainda persistem grandes diferenças no financiamento por aluno em todas as províncias. Registam-se diferenças notórias na dimensão dos sistemas de educação e no financiamento por aluno entre certas províncias do norte e do sul e entre as menos financiadas e as mais financiadas.

Um recente estudo efetuado pelo Movimento de Educação para Todos, adiante abreviado por MEPT (2018) constatou que no que tange a acessibilidade, ainda prevalece a inexistência de rampas que permitem a fácil locomoção das pessoas com deficiência. Igualmente notou-se que nos quartos de banho, a entrada que dá acesso directo à sanita, assim como o próprio modelo de sanita existente nas escolas visitadas pelo estudo, não permite que as pessoas com deficiência física (cadeirante) possam fazer o seu devido uso.

\section{Considerações finais}

O estudo documental sobre os percursos e os desafios da educação inclusiva na África Austral e em particular em Moçambique nos norteia a ter uma percepção do quão se mostra importante repensar na inclusão para além duma abordagem médica e prescritiva dos grupos alvos de inclusão, havendo necessidade de repensar na possibilidade de se enveredar por uma abordagem social em que se pensa a deficiência não como um estado físico, psicológico e sensorial limitador. Os estados membros da África Austral em que Moçambique é membro têm ainda notáveis desafios para a implementação dos diferentes documentos internacionais e regionais nos quais emanam as orientações sobre a educação inclusiva.

Os percursos seguidos pelo Moçambique constituem um passo que inspira confiança em proporcionar oportunidades de integração e inclusão dos alunos com deficiência nas escolas regulares de modo a cumprir com as orientações internacionais, porém, os desafios se mostram potentes considerando a multiplicidade de fatores que caracterizam os estados membros, em particular Moçambique. O caminho para uma efetiva inclusão escolar dos alunos com uma condição diferente perpassa as configurações sócio-históricas de cada estado membro indo até às particularidades dos indivíduos, isto é, há que considerar que a inclusão não se garante apenas com a criação de condições sociais, sendo pontual considerar questões atitudinais que são o maior desafio.

Ter uma legislação sobre a inclusão é fundamental para se conseguir o alcance dos objetivos que se presuma serem pontuais em cada estado membro, porém, a mudança atitudinal é crucial, uma vez que esta vai para além da legislação. Dum modo final, podemos considerar que a inclusão 


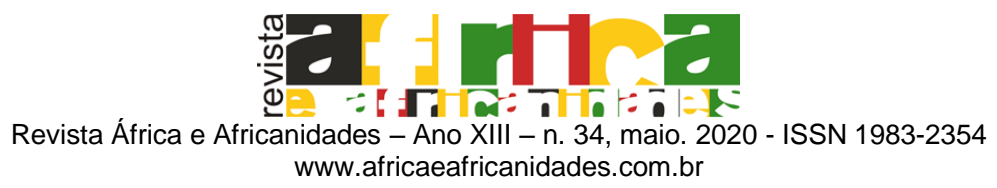

escolar de pessoas com deficiência pode ser possível por viés das interações sociais que a família, a comunidade e a sociedade em geral estabelecem no seu cotidiano, partindo de princípio de que o homem é um ser social e, fora da relação com a sociedade, jamais desenvolveria as qualidades, as características que são resultado do desenvolvimento metódico de toda a humanidade.

As condições do meio entram também em voga na medida em que o mesmo, segundo Vygotsky (2018)

é a fonte de desenvolvimento dessas características e qualidades especificamente humanas, em primeiro lugar, no sentido de que é nele que existem as características historicamente desenvolvidas e as peculiaridades inerentes ao homem por força de sua hereditariedade e estrutura orgânica. Ainda que elas existem em cada homem pelo fato de ele ser membro de um grupo social, ser uma unidade histórica que vive numa determinada época e em determinadas condições históricas. (VYGOTSKY, 2018, p. 90).

\section{Referências bibliográficas}

BONDE, Rui Amadeu. Políticas públicas de educação e qualidade de ensino em Moçambique. Rio de Janeiro, 2016.

INSTITUTO NACIONAL DE ESTATISTICA. RESULTADOS DEFINITIVOS do CENSO 2017 sobre o IV recenseamento Geral da População e Habitação. Maputo, 2017.

MANTOAN. Maria Teresa Eglér. Inclusão escolar: o que é? Por quê? Como fazer? São Paulo: Moderna, 2003.

MEDEIROS, Marcelo \& DINIZ, Debora. A nova maneira de se entender a deficiência e o envelhecimento. Brasília, 2004.

MOÇAMBIQUE. MAPEAMENTO CRÍTICO DA LEGISLAÇÃO MOÇAMBICANA RELATIVA ÀS PESSOAS COM DEFICIENNCIA: Um olhar para a futura reforma legal. MAPUTO, MARÇO DE 2017.

MOVIMENTO DE EDUCAÇÃO PARA TODOS. Estudo Sobre a Situação das Infraestruturas Escolares e seu Impacto no Acesso para as Crianças com Deficiência no Ensino Primário na Província de Maputo. Maputo, Outubro de 2018.

VALLE, Jan W.; CONNOR, David. J. Ressignificando a deficiência: da abordagem social às práticas inclusivas na escola. Porto Alegre: AMGH, 2014.

VYGOTSKY. L. S. Sete aulas de L. S VYGOTSKY sobre os fundamentos da Pedologia. Organização de Zoia prestes e Elizabeth Tunes.Trad. Cláudia da Costa Guimarães Santana - 1 ed. - Rio de Janeiro: Epapers, 2018. 